\title{
Combined Percutaneous Procedure in Patient with Lutembacher Syndrome: A Case Report and Real-World Experience Review
}

\author{
Quang Tan Phan ${ }^{\mathrm{a}, \mathrm{b}}$, Hieu Lan Nguyen ${ }^{\mathrm{c}}$, Tai Duc Le ${ }^{\mathrm{d}}$, WangSoo Lee ${ }^{\mathrm{b}}$, \\ HoYoun Won ${ }^{\mathrm{b}}$, Seung Yong Shin ${ }^{\mathrm{b}}$, Saima Sharmin ${ }^{\mathrm{b}}$, \\ Truong Quang Nguyen ${ }^{\mathrm{a}}$, SangWook Kim ${ }^{\mathrm{b}}$ e
}

\begin{abstract}
Even cardiac surgery has been accepted as the standard therapy for Lutembacher syndrome, a combination of congenital ostium secundum atrial septal defect (ASD) and acquired mitral valve stenosis (MVS), it also owns many limitations and disadvantages. Therefore, seeking for a less invasive therapy with the same efficacy may be worthwhile. Thanks to the development in technology and experience gaining in cardiovascular intervention, the combination of the two proved effective procedures, including percutaneous MVS treatment using balloon valvuloplasty and percutaneous ASD closure using atrial septal occluders, can be utilized as an attractive alternative therapy for these conditions. Here, we present a successful percutaneous intervention in Lutembacher syndrome using the combination of mitral balloon valvuloplasty and ASD device closure and thoroughly review the experience of using this combined procedure existing in the literature.
\end{abstract}

Keywords: Lutembacher syndrome; Percutaneous intervention; Atrial septal defect; Mitral valve stenosis

\section{Introduction}

Lutembacher syndrome is a rare combination of congenital ostium secundum atrial septal defect (ASD) and acquired mitral

Manuscript submitted September 1, 2018, accepted September 11, 2018

antervention Center, Quang Nam Central General Hospital, Quang Nam 562314, Vietnam

' Intervention Center, Chung-Ang University Hospital, Seoul 06973, Korea

'Intervention Center, Vietnam National Heart Institute, Hanoi 115289, Vietnam

Interventional Cardiology Department, Nghe An Province General Hospital, Nghe An, Vietnam

${ }^{\mathrm{e} C o r r e s p o n d i n g ~ A u t h o r: ~ S a n g-W o o k ~ K i m, ~ C a r d i o v a s c u l a r ~ R e s e a r c h ~ C e n t e r, ~}$ Chung-Ang University Hospital, Seoul 06973, Korea.

Email: swivus@gmail.com

doi: https://doi.org/10.14740/cr776w valve stenosis (MVS) with female predominance and unfavorable long-term progression [1-3]. Although open heart surgery is still considered the treatment of choice to fix the both conditions at the same time, it is associated with surgical complications, long hospital stay, sternotomy, skin scar, psychosocial effect and higher surgical risk if reoperation for mitral valve restenosis is necessary later. Because the percutaneous treatment of MVS using balloon valvuloplasty and percutaneous closure of ASD using atrial septal occluders are widely considered safe and efficacious [4-11], these procedures can be utilized as an alternative therapy for the combined conditions in Lutembacher syndrome.

\section{Case Report}

We present a case of 59-year-old female who was diagnosed with Lutembacher syndrome 3 years ago but refused to have cardiac surgery and was being maneged with medicine. She hospitalized because of dyspnea and palpitation that was increased gradually and unberable recently. The patient's exercise tolerance was reduced and the New York Heart Association (NYHA) functional class increased from class II at the last check-up 30 days before to class IV at this hospitalization. Phisical examination showed loud first heart sound, fixed and wide splitting of the second heart sound and mid-diastolic rumbling murmur at the apex. Echocardiography (ECG) showed atrial fibrillation, right atrial hypertrophy, right ventricular hypertrophy and incomplete right bundle branch block. The cardiothoracic ratio was 0.65 on chest radiography. ECG showed a 22-mm secundum ASD with left to right shunt and good surrounding rims. There was also severe MVS with the mitral valve area (MVA) of $0.88 \mathrm{~cm}^{2}$ by planimetry, Wilkin score of 7/16, mean transmitral gradient of $15 \mathrm{~mm} \mathrm{Hg}$ and insignificant mitral regurgitation. The left atrium, right atrium and right ventricle were dilated and no thrombus was detected. On catheterization, the $\mathrm{Qp} / \mathrm{Qs}$ ratio was 4.6, the mean pulmonary arterial pressure was $36 \mathrm{~mm} \mathrm{Hg}$, the mean left atrial pressure was $22 \mathrm{~mm} \mathrm{Hg}$ and the mean transmitral gradient was $14 \mathrm{~mm}$ $\mathrm{Hg}$. Because the patient refused to have cardiac surgery, the symptoms were getting worse with optimal medication, and both the ASD and MVS appeared to be suitable for transcath- 

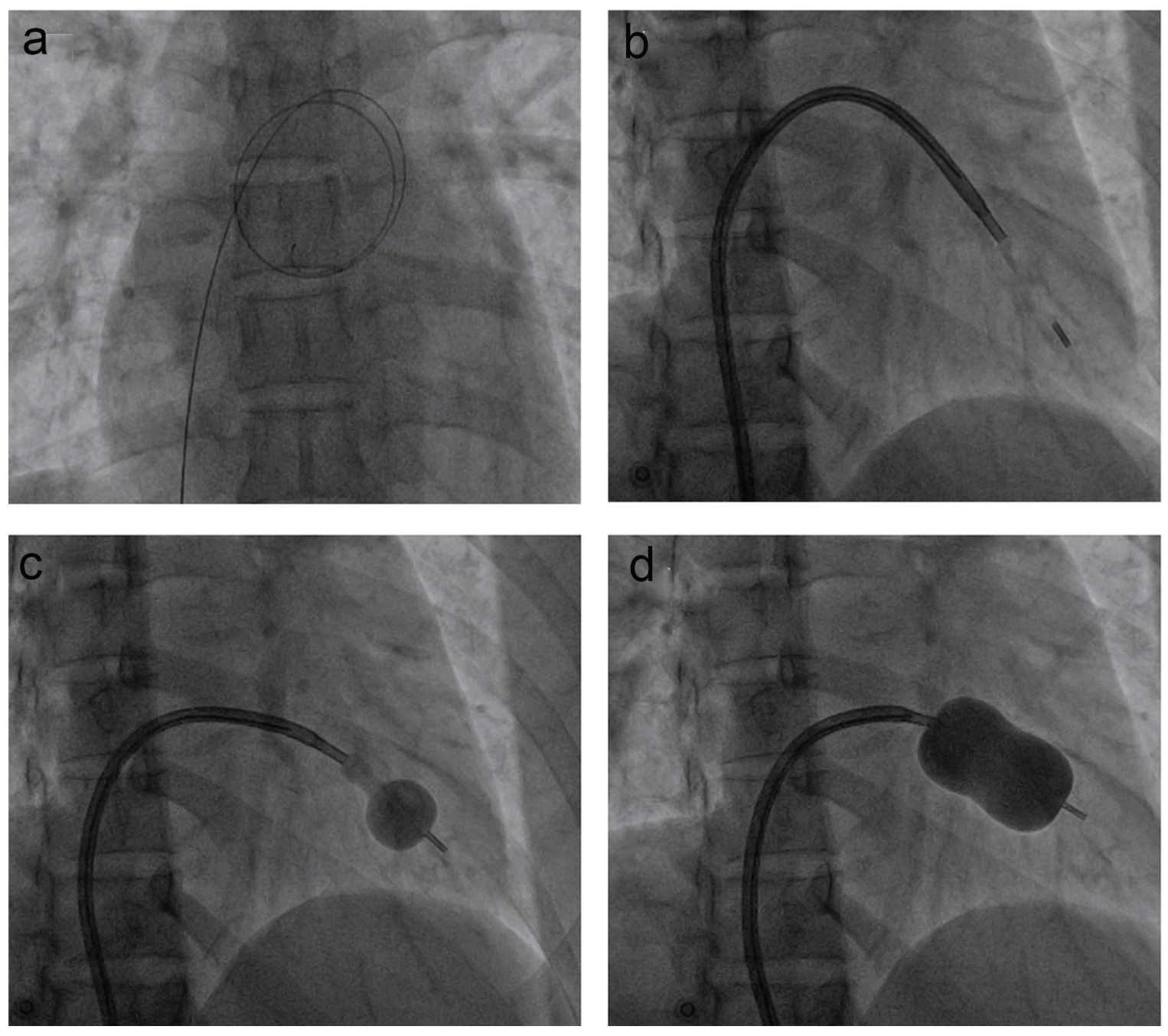

Figure 1. The percutaneous mitral valvuloplasty procedure. (a) The wire crosses from right atrium to the left atrium through the ASD; (b) the Inoue balloon is introduced to the left ventricle; (c) the Inoue balloon is partly inflated and withdrawn toward mitral valve; (d) the balloon is fully expanded.

eter treatment, we planned to perform mitral valvuloplasty and ASD closure in the same setting after explaining the benefits, risks and obtaining patient consent form.

The transcatheter mitral valvuloplasty and ASD closure procedures were performed with preparations, devices and approaches that were described in the literature [8, 9, 12-14]. The mitral valvuloplasty was done first with a 24-mm Inoue balloon (Toray Medical Co., Japan) through the existing ASD (Fig. 1). After valvuloplasty, the MVA was $1.92 \mathrm{~cm}^{2}$, the mean left atrial pressure was $11 \mathrm{~mm} \mathrm{Hg}$, the mean transmitral gradient was $6 \mathrm{~mm} \mathrm{Hg}$ and the Qp/Qs ratio was 2.8:1. Subsequently, the ASD was successfully closed using a 26-mm Cocoon Septal Occluder (Vascular Innovations Co., Thailand) without complication (Fig. 2). The echocardiogrphy $24 \mathrm{~h}$ after the procedure showed that the ASD device was in good position with trivival residual shunt and mild mitral regurgitation. The patient was discharged 5 days after the procedure uneventfully. One-year follow-up examinations showed that patient clinical presentations were significantly improved and NYHA class re- duced to class II. ECG showed the Cocoon Septal Occluder was in good position without residual shunt, the MVA was maintained at $1.87 \mathrm{~cm}^{2}$ (Fig. 3) and the mean pulmonary arterial pressure decreased to $19 \mathrm{~mm} \mathrm{Hg}$.

\section{Combined percutaneous procedure for Lutembacher syn- drome reported in the literature}

There has been a serial of case reports in the lieterature about the combination of balloon mitral valvuloplasty and ASD device closure in Lutembacher syndrome (Table 1). Acordingly, the median of age at the time of combined procedure was 38 years old (17 - 61 years old) and most of the patients were female $(87.5 \%)$. The patients commonly presented with a history of rheumatic heart disease $(66.7 \%)$, dyspnea $(95.8 \%)$ and palpitations (43.8\%). Physical examination ussually detected diastolic murmur at apex $(79.2 \%)$, fixed splitting of second heart sound $(75.0 \%)$, loud first heart sound (70.8\%) and sys- 

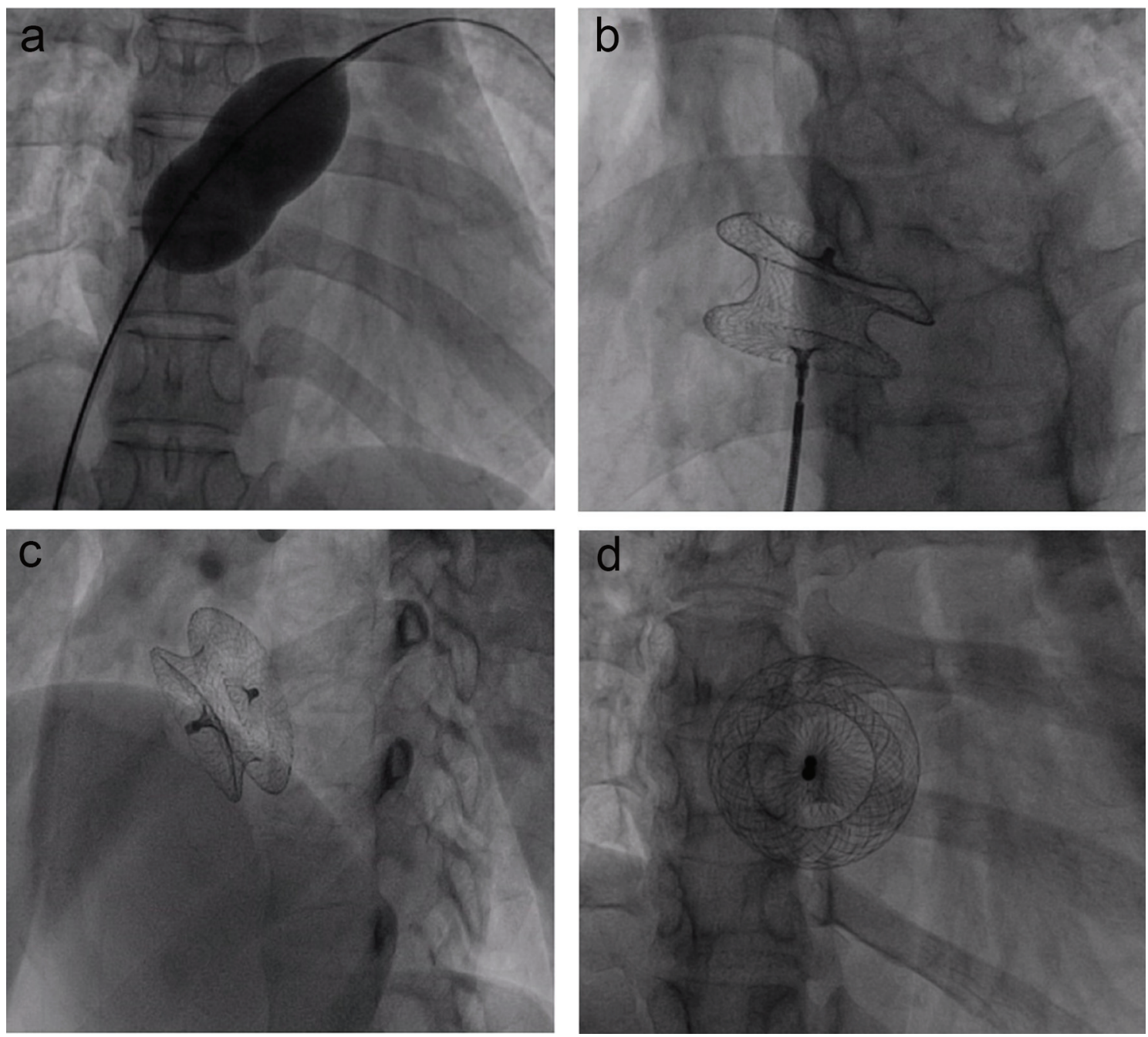

Figure 2. The percutaneous ASD closure procedure. (a) The sizing balloon is advanced through the superstiff wire and inflated at the atrial septum until the waist is clearly seen; (b) the device is selected and fully opened at the atrial septal defect; (c) the device after release at the anterior posterior view; (d) the device is in good position at the left anterior oblique and cranial view.

tolic murmur at pulmonary area (45.8\%). Most of the patients had cardiomegaly on chest radiography $(91.2 \%)$ and more than haft of them had NYHA class $\geq 3(54.2 \%)$. The most common signs found on ECG were incomplete right bundle branch block (75.0\%), right atrial and/or right ventricular hypertrophy $(45.8 \%)$ and atrial fibrillation (37.5\%). The median of ASD size was $19 \mathrm{~mm}(13-30 \mathrm{~mm})$; the mean MVA was $1.0 \pm 0.3$ $\mathrm{cm}^{2}\left(0.4-1.5 \mathrm{~cm}^{2}\right)$ with the median of Wilkin score of $6.5(5-$ 8). All patients had left to right shunt through the ASD except one with bi-directional shunt [15].

The median of baloon cahether size for mitral valvuloplasty was $25 \mathrm{~mm}(24-28 \mathrm{~mm})$ and the median of device size for ASD closure was $26 \mathrm{~mm}(14-40 \mathrm{~mm})$. After the procedure, along with the increase in the MVA $(1.0 \pm 0.3-2.0 \pm$ $0.44 \mathrm{~cm}^{2}$ ), there were also significant decreases in the mean pulmonary arterial pressure $(29.2 \pm 10.4-19.3 \pm 6.1 \mathrm{~mm} \mathrm{Hg})$, mean left atrial pressure $(15.6 \pm 5.4-7.33 \pm 2.65 \mathrm{~mm} \mathrm{Hg})$ and mean transmitral pressure gradient $(11.9 \pm 5.9-3.27 \pm 2.2$ $\mathrm{mm} \mathrm{Hg}$ ) (Table 2). Complete closure after ASD closure was seen in $91.7 \%$ of patients $24 \mathrm{~h}$ after the procedure and there was no residual shunt detected in all patients during followup. The most commonly used balloon for mitral valvularplasty was Inoue balloon (79.2\%) and the most commonly used ASD closure device was Amplazer Septal Occluder (62.5\%). While most of the combined procedures were performed within the same setting, in some center, the ASD closure was performed after mitral valvuloplasty $48-72 \mathrm{~h}$ to have enough time for more careful hemodynamic evaluation after the first procedure [16]. Besides, while ASD was used as a natural passage for mitral valvuloplasty in most procedures, some authors suggested making a low septal puncture that separated from the ASD to get more support for balloon orientating and crossing the mitral valve [17].

Major complications were rarely occurred during and after this combined procedure. In only one patient, ASD closure device malposition was detected after deployment, but the device was safely retrieved transcatheterly and another larger device was then successfully implanted [18]. All procedures showed 

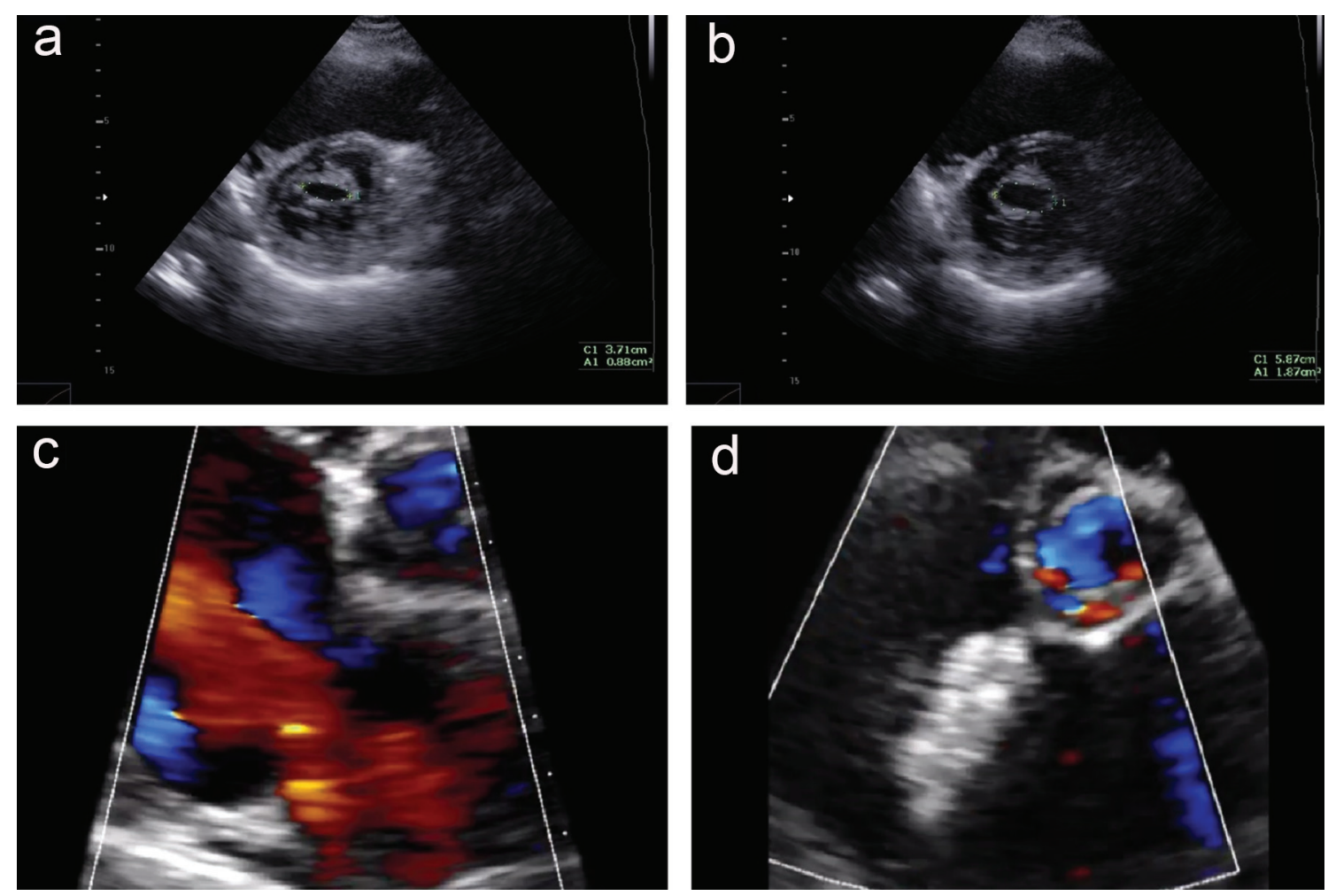

Figure 3. The echocardiography exam before and 12 months after procedure. (a) Mitral valve at parasternal short axis view, before mitral valvuloplasty; (b) mitral valve at parasternal short axis view, after mitral valvuloplasty; (c) the color Doppler echocardiography at parasternal short axis view shows an ASD with left to right shunt; (d) the Cocoon Septal Occluder is in good position without residual shunt.

insignificant mitral regurgitation after mitral balloon valvuloplasty except in one patient, mitral regurgitation degree increased from grade $2 / 4$ to grade $3 / 4$ without significant clinical sequence [19]. The sucessful procedures and favorable shortand mid-term outcome in these reports demonstrated the feasibility, safety and efficacy of the combined procedure of mitral valvuloplasty using a variety of balloon catheters and ASD closure using different device types in Lutembacher syndrome.

\section{Discussion}

Lutembacher syndrome was first described by Lutembacher in 1916, including the combination of congenital ASD and acquired MVS. In this combination, because the augmented left to right shunt of the significant ASD helps to reduce the the left atrial pressure and transmitral pressure gradient, it may delay the expression of MVS clinical symptoms [3, 20,21]. However, because of the early development of severe pulmonary arterial hypertension, most of the patients will finally end up with decompensated right heart failure and other complications [22-24]. Even cardiac surgery is still the treatment of choice for Lutembacher syndrome, transcatheter therapy has been presented as an attractive and feasible alternative therapy $[21,25-30]$. In our case, the patient and family refused to have cardiac surgery, the clinical symptoms were severe, and both MVS and ASD were suitable for transcatheter treatment, we decided to utilize this alternative therapy for the patient.

In the first combined transcatheter procedure for palliative treatment purpose in a patient with Lutembecher syndrome, severe aortic stenosis and very high pulmonary arterial pressure, Ruiz et al combined ASD closure using Lock's clamshell occluder with mitral and aortic balloon valvotomies to reduce the risk for the cardiac surgery [15]. However, the patient then refused cardiac surgery after the procedure and expired suddenly 8 weeks later. The first successful transcatheter procedure for Lutembecher syndrome was performed by Joseph et al in 1999, including the combination of mitral valvularplasty using Joseph balloon catheter and ASD device closure using Amplatzer Septal Occluder [16]. In later reports, the interventionalists used different types of devices for the two procedures (Table 1). In Lutembacher syndrome, although there is no risk of septal puncture because the congenital ASD can be used as the convenient passageway for mitral valvular plasty, the unstable of the Inoue balloon catheter during crossing or positioning at the mitral valve due to large ASD may make the mitral valvularplasty even more challenging [2, 22]. In these setting, if the conventional Inoue maneuver approach is unsuccessful, some alternative methods may be utilized to overcome the difficulties of mitral valve crossing such as over the wire technique, balloon floatation catheter, catheter sliding method, reverse loop method or making a large curve of the stylet $[18,22,31]$. In our case, the manipulation of the Inoue balloon catheter was convinient and the ASD device closure was 
Table 1. Transcatheter Treatment for Lutembacher Syndrome in Literature

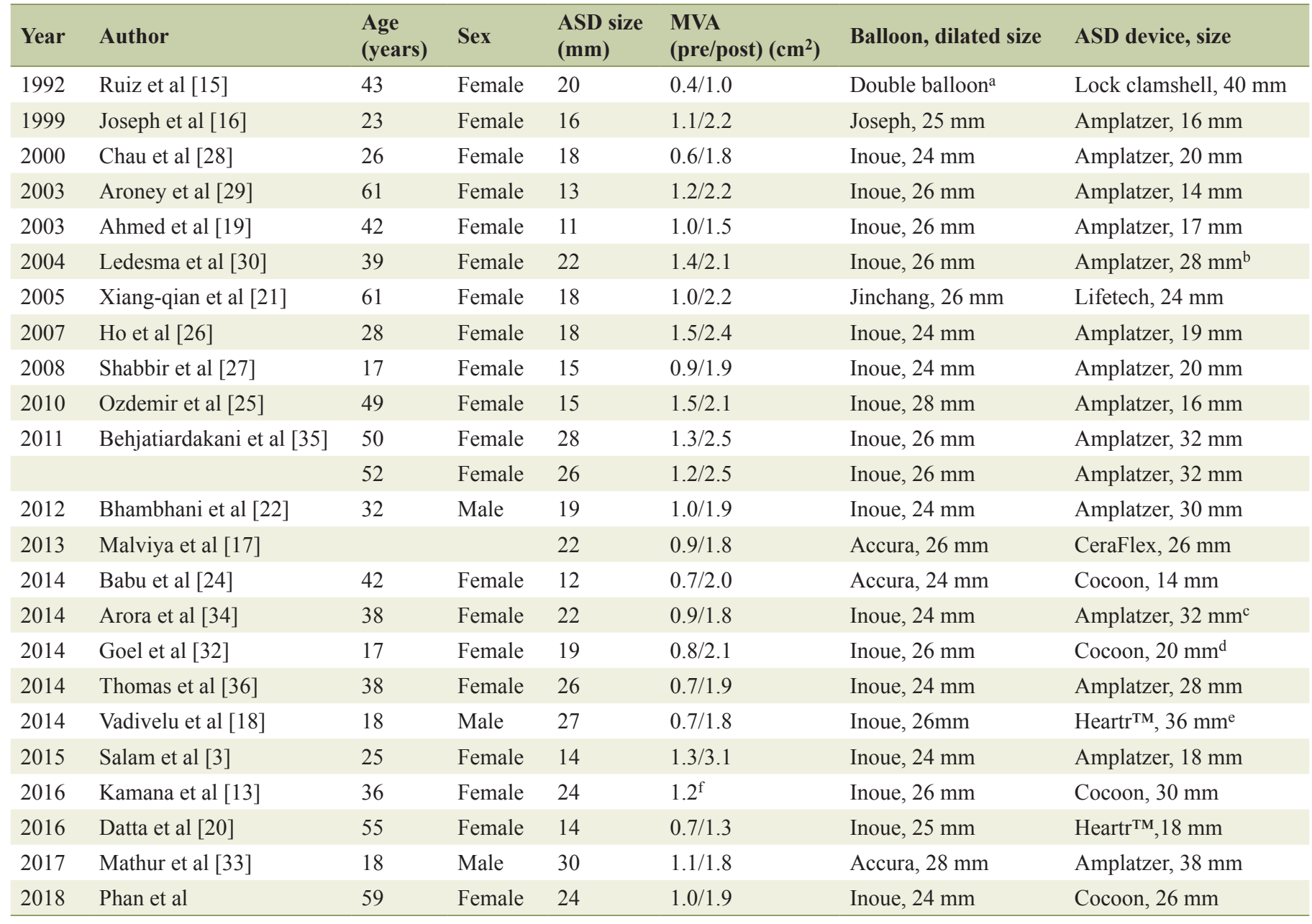

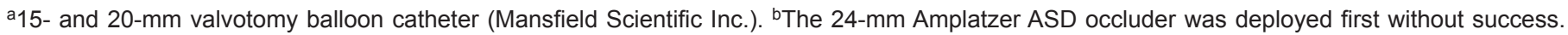
${ }^{\mathrm{C}}$ The first 30-mm Amplazer device deployment was failed. ${ }^{\mathrm{d} A S D}$ closure was performed $48 \mathrm{~h}$ after mitral valvuloplasty. ${ }^{\mathrm{e}}$ The first $30-\mathrm{mm}$ Amplazer device was mal-position and retrieved percutaneously. ${ }^{f}$ The post procedural MVA was not available.

smoothly performed. This might be due to the good ASD rims that provided adequate support for the balloon positioning and later steps [32].

The changes of cardiac structures regarding to the coexisting of ASD and MVS were reported to increase the risks of complications during and after the ASD closure procedure $[18,33]$. Even complications during combined procedure has been rarely reported, some severe adverse events may happen during and after the procedure, including device embolization, stroke, heart block, severe mitral regurgitation, cardiac tamponade, etc. [34]. Some authors tended to choose undersized mitral valvuloplasty balloon catheter and oversized ASD closure device to reduce the risk of severe mitral regurgitation and device embolization [20, 28, 30, 32]. Besides, proper patient selection, careful pre-procedural assessment and operator skill improvement may be the crucial keys to prevent complications

Table 2. The Echocardiographic and Hemodynamic Changes After the Procedure

\begin{tabular}{llll}
\hline Parameter & Before procedure $(\mathbf{n}=\mathbf{2 4})$ & After procedure $(\mathbf{n}=\mathbf{2 4})$ & P \\
\hline Mitral valve area $\left(\mathrm{cm}^{2}\right)$ & $1.00 \pm 0.29$ & $2.00 \pm 0.43$ & $<0.001$ \\
Mean pulmonary arterial pressure $(\mathrm{mm} \mathrm{Hg})$ & $29.2 \pm 10.4$ & $19.3 \pm 6.1$ & $<0.001$ \\
Mean left atrial pressure $(\mathrm{mm} \mathrm{Hg})$ & $15.6 \pm 5.4$ & $7.33 \pm 2.65$ & $<0.001$ \\
Mean transmitral pressure $(\mathrm{mm} \mathrm{Hg})$ & $11.9 \pm 5.9$ & $3.27 \pm 2.2$ & $<0.001$ \\
Qp/Qs* & $3.62 \pm 1.09$ & $1.83 \pm 0.56$ & $<0.001$ \\
\hline
\end{tabular}

Qp/Qs: pulmonary/systemic blood flow ratio. *Immediately after mitral valvuloplasty. 
of this procedure.

In real-world practice, open heart surgery is the therapy of choice for most of the complex or combined cardiac anomalies. However, the combination of ASD and MVS in Lutembacher syndrome anatomically makes it feasible for the transcatheter therapy. In comparion with cardiac surgery, the advantages of transcatheter treatment of Lutembacher are cheaper, avoiding complications of cardiac surgery and anesthesia, faster recovery, avoiding sternotomy and skin scar, reducing psychological effect and shorter hospital stay $[35,36]$. However, an important issue of this combined procedure is that the repeated trans-septal mitral valvularplasty cannot be performed again in the case of the mitral valve restenosis that may occur after the first procedure. Because the mitral valve restenosis rate after mitral valvuloplasty is quite high, the need to re-perform this procedure is also common [17, 33, 36, 37]. However, by using this combined procedure approach, the presence of ASD closure device makes it impossible for the transcatheter mitral valvularplasty using transseptal technique. Therefore, in cases with high probability of mitral restenosis after valvularplasty, cardiac surgery with valve replacement may be the best option. If the surgery cannot be selected in these cases and the right heart failure is severe even with optimal medical treament, a single palliative mitral valvularplasty procedure may be beneficial if the effect of ASD on the hemodynamic is not severe after mitral valvularplasty [32]. In other cases with the mitral restenosis occurring after combined procedure, the retrograde trans-arterial mitral valvuloplasty may be helpful $[25,35,38]$. However, in comparison with conventional mitral valvuloplasty, this technique may be more difficult and may not well be adopted by every institute. Currently, there is no report about dealing with mitral valve restenosis after combined procedure of mitral valvuloplasty and ASD closure in Lutembacher syndrome.

\section{Conclusions}

With the development in technology and experience gaining in cardiovascular intervention, the combination of balloon mitral valvuloplasty and ASD device closure in Lutembacher syndrome is considered feasible, safe and efficacious. This therapy can be used as an effective alternative to cardiac surgery in careful selected patients. A prospective data with larger serial of patients and longer follow-up may be necessary to address the long-term outcome of this combined procedure.

\section{Acknowledgments}

We acknowledge that all authors listed meet the authorship criteria according to the latest guidelines of the International Committee of Medical Journal Editors, and all authors are in agreement with the manuscript.

\section{Conflict of Interest}

No financial disclosures or conflict of interest.

\section{References}

1. Aminde LN, Dzudie A, Takah NF, Ngu KB, Sliwa K, Kengne AP. Current diagnostic and treatment strategies for Lutembacher syndrome: the pivotal role of echocardiography. Cardiovasc Diagn Ther. 2015;5(2):122-132.

2. Aminde LN, Dzudie AT, Takah NF, Ambassa JC, Mapoh SY, Tantchou JC. Occurrence of Lutembacher syndrome in a rural regional hospital: case report from Buea, Cameroon. Cardiovasc Diagn Ther. 2014;4(3):263-266.

3. Salam AMBA, Islam SKZ, Hasan KA, et al. Trans-catheter Treatment of Lutembacher Syndrome - A case report. Cardiovasc J. 2015;7(2):162-165.

4. Geva T, Martins JD, Wald RM. Atrial septal defects. Lancet. 2014;383(9932):1921-1932.

5. Kazmouz S, Kenny D, Cao QL, Kavinsky CJ, Hijazi ZM. Transcatheter closure of secundum atrial septal defects. J Invasive Cardiol. 2013;25(5):257-264.

6. Moore J, Hegde S, El-Said H, Beekman R, 3rd, Benson L, Bergersen L, Holzer R, et al. Transcatheter device closure of atrial septal defects: a safety review. JACC Cardiovasc Interv. 2013;6(5):433-442.

7. Tomai F, Gaspardone A, Versaci F, Ghini AS, Altamura L, De Luca L, Gioffre G, et al. Twenty year follow-up after successful percutaneous balloon mitral valvuloplasty in a large contemporary series of patients with mitral stenosis. Int J Cardiol. 2014;177(3):881-885.

8. Mayes CE, Cigarroa JE, Lange RA, Hillis LD. Percutaneous mitral balloon valvuloplasty. Clin Cardiol. 1999;22(8):501-503.

9. Chmielak Z, Klopotowski M, Demkow M, Konka M, Hoffman P, Kukula K, Kruk M, et al. Percutaneous mitral balloon valvuloplasty beyond 65 years of age. Cardiol J. 2013;20(1):44-51.

10. Alnasser S, Lee D, Austin PC, Labos C, Osten M, Lightfoot DT, Kutty S, et al. Long term outcomes among adults post transcatheter atrial septal defect closure: Systematic review and meta-analysis. Int J Cardiol. 2018;270:126132.

11. Telila T, Mohamed E, Jacobson KM. Endovascular therapy for rheumatic mitral and aortic valve disease: review article. Curr Treat Options Cardiovasc Med. 2018;20(7):59.

12. Nobuyoshi M, Arita T, Shirai S, Hamasaki N, Yokoi $\mathrm{H}$, Iwabuchi M, Yasumoto $\mathrm{H}$, et al. Percutaneous balloon mitral valvuloplasty: a review. Circulation. 2009;119(8):e211-219.

13. Kamana VK, Shetty R, Krishnan AM, Chowdary RK, Malpe UP. Is Transoesophageal Echocardiography Necessary for the Percutaneous Management of Lutembacher Syndrome: A Case Report. J Clin Diagn Res. 2016;10(10):OD08-OD09.

14. Dalvi BL, Jain SA. Atrial septal defect: step-by-step catheter closure. Journal of Structural Heart Disease. 2016;2(1):15-32.

15. Ruiz CE, Gamra H, Mahrer P, Allen JW, O'Laughlin MP, Lau FY. Percutaneous closure of a secundum atrial septal defect and double balloon valvotomies of a severe mitral 
and aortic valve stenosis in a patient with Lutembacher's syndrome and severe pulmonary hypertension. Cathet Cardiovasc Diagn. 1992;25(4):309-312.

16. Joseph G, Abhaichand Rajpal K, Kumar KP. Definitive percutaneous treatment of Lutembacher's syndrome. Catheter Cardiovasc Interv. 1999;48(2):199-204.

17. Malviya A, Saha SK, Mishra A. Substantive treatment of Lutembacher's syndrome by the trans-septal puncture technique: a case report and review. Heart Asia. 2013;5(1):222-224.

18. Vadivelu R, Chakraborty S, Bagga S. Transcatheter therapy for Lutembacher's syndrome: The road less travelled. Ann Pediatr Cardiol. 2014;7(1):37-40.

19. Ahmed WH, Al-Shaibi KF, Chamsi-Pasha H, Abdelmenem A. Non-surgical correction of Lutembacher syndrome. Saudi Med J. 2003;24(3):307-308.

20. DattaSK, Sethi KK, Singh S, et al. Complete percutaneous management of Lutembacher syndrome with severe pulmonary hypertension in a middle aged Indian female: is this the magic wand? Global J Med Clin Case Reports. 2016;3(1):022-025.

21. Shen XQ, Zhou SH, Zhou T, Qi SS, Fang ZF, Lv XL. Transcatheter treatment of Lutembacher syndrome. Chin Med J (Engl). 2005;118(21):1843-1845.

22. Bhambhani A, Somanath HS. Percutaneous treatment of Lutembacher syndrome in a case with difficult mitral valve crossing. J Invasive Cardiol. 2012;24(3):E54-56.

23. Cheng TO. Coexistent atrial septal defect and mitral stenosis (Lutembacher syndrome): An ideal combination for percutaneous treatment. Catheter Cardiovasc Interv. 1999;48(2):205-206.

24. Babu MB, Rajasekhar D, Vanajakshamma V. Percutaneous transcatheter treatment of Lutembacher syndrome. J NTR Univ Health Sci. 2014;3:180-182.

25. Ozdemir AO, Kumbasar D, Dincer I, Atmaca Y. [Percutaneous treatment of Lutembacher syndrome: a case report]. Turk Kardiyol Dern Ars. 2010;38(1):47-49.

26. Ho CL, Liang $\mathrm{KW}, \mathrm{Fu} \mathrm{YC}$, Jan SL, Lin MC, Chi CS, Hwang B. Transcatheter therapy of Lutembacher syndrome. J Chin Med Assoc. 2007;70(6):253-256.

27. Shabbir M, Ahmed W, Akhtar K. Transcatheter treatment of Lutembacher's syndrome. J Coll Physicians Surg Pak. 2008;18(2):105-106.

28. Chau EM, Lee CH, Chow WH. Transcatheter treatment of a case of Lutembacher syndrome. Catheter Cardiovasc Interv. 2000;50(1):68-70.

29. Aroney C, Lapanun W, Scalia G, Parsonage W. Transcatheter treatment of Lutembacher syndrome. Intern Med J. 2003;33(5-6):259-260.

30. Ledesma M, Martinez P, Cazares MA, Feldman T. Transcatheter treatment of Lutembacher syndrome: combined balloon mitral valvuloplasty and percutaneous atrial septal defect closure. J Invasive Cardiol. 2004;16(11):678679.

31. Khandenahally Shankarappa R, Dwarakaprasad R, Karur S, Bachahally Krishnanaik G, Panneerselvam A, Cholenahally Nanjappa M. Balloon mitral valvotomy for calcific mitral stenosis. JACC Cardiovasc Interv. 2009;2(3):263264.

32. Goel S, Nath R, Sharma A, Pandit N, Wardhan H. Successful percutaneous management of Lutembacher syndrome. Indian Heart J. 2014;66(3):355-357.

33. Mathur R, Sanghvi S, Baroopal A. Percutaneous Transcatheter Treatment of Lutembacher Syndrome. J Assoc Physicians India. 2018;66(1):100-101.

34. Joly H, Villemin J. [Technic of definitive collapse and its place in the treatment of pulmonary tuberculosis]. Minerva Med. 1953;44(8):215-217.

35. Behjatiardakani $M$, Rafiei $M$, Nough $H$, et al. Transcatheter therapy of Lutembacher syndrome: a case report. Acta Medica Iranica. 2011;49(5):327-330.

36. Thomas VG, Vinod RR, Sanjeev GV. A case report of trans-catheter treatment of Lutembacher's syndrome. Journal of Indian College of Cardiology. 2015;5:173-175.

37. Fawzy ME. Percutaneous mitral balloon valvotomy. Catheter Cardiovasc Interv. 2007;69(2):313-321.

38. Stefanadis CI, Stratos CG, Lambrou SG, Bahl VK, Cokkinos DV, Voudris VA, Foussas SG, et al. Retrograde nontransseptal balloon mitral valvuloplasty: immediate results and intermediate long-term outcome in 441 cases - a multicenter experience. J Am Coll Cardiol. 1998;32(4):1009-1016. 